\title{
Modal Analysis of a DFIG-Based Wind Farm Interfaced with a Series Compensated Network
}

\author{
Lingling Fan, Senior Member, IEEE,Chanxia Zhu, Student Member, IEEE, Zhixin Miao, Senior Member, IEEE, \\ Minqiang $\mathrm{Hu}$
}

\begin{abstract}
Interests of subsynchronous resonance (SSR) in series compensated electric networks with wind power penetration have arisen recently. To better understand the nature of such systems, modal analysis of a doubly-fed induction generator (DFIG)-based wind energy system interconnected with a series compensated electric network is conducted in this paper. The system model is built in Matlab/Simulink. The major contributions of the paper include: (i) identification of the four system modes (SSR, supersynchronous, electromechanical and shaft modes) of a DFIG-based wind farm interfaced with a series compensated network, (ii) investigation of the impacts of various parameters and operating conditions on those modes and (iii) prediction of the dynamic performance of the system using modal analysis and confirmation of such prediction via time-domain simulation results.
\end{abstract}

Index Terms-DFIG, SSR, Participation Factor, Modal Analysis, Eigenvalues

\section{INTRODUCTION}

$\mathbf{S}$ UBSYNCHRONOUS resonance (SSR) phenomenon happened in series compensated transmission networks and caused extensive damage to turbine-generator shafts in power plants in history [1]. It is of great interest to the utility industry. With the increasing penetration of wind power in transmission networks, interests of SSR phenomenon in wind energy systems have arisen. In regions where series compensated long distance transmission networks are used and abundant wind power sources are available, the interaction of wind power and the network LC resonance modes is especially of high interest. Several recent research papers have addressed SSR issues in wind farms interconnected with series compensated networks [2]-[4].

Reference [2] discusses SSR phenomena of a self-excited double induction generator based wind farm interconnected with a series-compensated network. Impacts of wind speeds and compensation levels on SSR are investigated. FACTS devices such as TCSC and SVC are used to demonstrate how to mitigate SSR in such systems. Reference [3] investigates the small signal stability issues of a DFIG-based wind farms interconnected with a series compensated network. Though the word "SSR" is not mentioned in the paper, the dominant mode is the electric network SSR mode. Compared with the wind farm in [2], the DFIG-based wind farm in [3] is equipped with back to back converters and has control capabilities. Therefore, besides wind speeds and compensation levels, impacts of the

L. Fan and Z. Miao are with Department of Electrical Engineering, University of South Florida, Tampa, FL 33620. C. Zhu and M. Hu are with Southeast University. Email: linglingfan@usf.edu. Phone: (813)974-2031. parameters of the current control loops of the converters on small signal stability are investigated. In [4], the focus is on control design and testing using STATCOM to mitigate SSR in a wind energy system similar as that in [2].

A thorough small signal analysis or modal analysis of series compensated networks with wind power penetration can improve the understanding of such systems and facilitate SSR mitigation. As DFIG is the state-of-the-art wind generator technology, DFIG-based wind energy systems should be the focus of such investigation. Though Reference [3] presents a small signal analysis of a DFIG-based wind farm interconnected with a series compensated network, only the SSR mode is identified as the dominant mode and further studies. All other system modes are not presented. Furthermore, the shaft system is modeled as one-mass system and hence the shaft mode of the wind turbine cannot be observed. Small signal analysis of DFIG-based wind energy systems has also been performed in [5] and [6] with the shaft mode captured. However, the network dynamics are ignored in the models and SSR phenomena cannot be captured. In addition, a constant turbine power is assumed and only one wind speed is discussed in [5] and [6].

The presentation of an overview picture of the system modes under a changing operating condition (e.g., the varying wind speeds) is the purpose of this paper. Small signal analysis or modal analysis will be performed to identify the system modes and their characteristics. Also, time responses of the electrical and mechanical system variables such as voltages, currents, speeds and torques will be predicted using modal analysis and confirmed by nonlinear time-domain simulations in Matlab/Simulink. This study will lay the foundation for future works in SSR mitigation and stability enhancement in systems with wind penetration.

The rest of the paper is organized as follows. Section II describes the study system and the models of such system. Section III presents modal analysis, participation factors, and time response coefficients. Identification of the system modes is presented in Section IV using eigenvalue analysis and participation factors. Section $\mathrm{V}$ presents the time response coefficients of the study system and the nonlinear time-domain simulation results. The relationship between the time response coefficients and the dynamic responses in simulation results is explained. Section VI concludes the paper.

\section{STUdy System}

The study system is shown in Fig. 1 where a DFIGbased wind farm (100 MW from aggregation of $2 \mathrm{MW}$ units) 


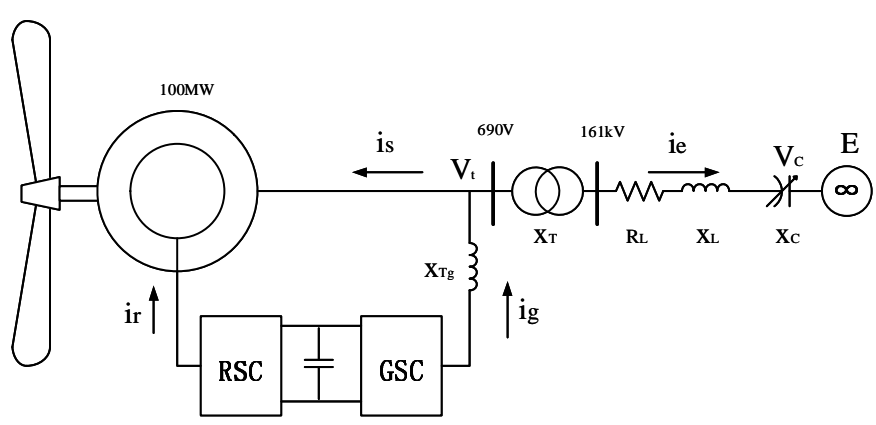

Fig. 1. The system structure.

is connected to a series-compensated line whose parameters correspond to the IEEE first benchmark model for SSR studies [7]. The wind farms can be considered as coherent generators and can be represented by one large DFIG. This approach has been practiced in system studies [8]. The parameters of a single 2MW DFIG and the equivalent DFIG are listed in Appendix Table IX. The parameters of the network are listed in Appendix Table X.

The study system consists of an equivalent DFIG, its back to back rotor side converter (RSC) and grid-side converter (GSC), the drive train and the transmission line. A 6th order model is used to describe the dynamics of the stator and rotor currents of an induction generator in the synchronous reference frame [9]. A two-mass model is used to describe the dynamics of the rotor and the drive train [5]. The parameters of the shaft are given in Appendix Table XI. The high switching dynamics at the order of kilo $\mathrm{Hz}$ of the IGBT-based converter are ignored in the modeling process while both the inner and outer control loops of the RSC and GSC are taken into consideration. The dynamics of the capacitor in the dc-link between the RSC and the GSC is modeled as a first-order differential equation.

Unlike models for transient stability where the dynamics of the electric network are ignored, in this study, to demonstrate the electric network LC resonance mode, the dynamics of the current through the inductor and the dynamics of the voltage across the series-connected capacitor are modeled in differential equations. Further, since the wind farm is modeled in the synchronous reference frame, the transmission network should also be modeled in the same reference frame for simulations and small signal analysis [10]. The details of the models and the modeling procedure can be found in [11] and [12].

In this study, the RSC and GSC control loops are modeled, where the inner loops are current control loops and the outer loops are the power/voltage control loops. For the RSC control loops, the $q d$-axis loops are to track the active and reactive power references respectively. Maximum power point tracking is used to determine the active power order of the $q$-axis control. For the GSC control loops, the $q d$-axis loops are to track the dc-link reference voltage and the wind farm terminal voltage respectively. The detailed description of the GSC control scheme can be found in [13] and and the detailed description of the control schemes of both converters can be found in [12].

\section{Modal Analysis, Participation Factors, And Time Response CoEfFicients}

Modal analysis or small signal analysis has been popularly used in power system stability analysis. The application areas include low frequency oscillation stability [14] and SSR stability [15]. In [16], modal analysis and its applications in both areas are covered. More recently, high bandwidth (six-sample per cycle) model is used in accurate eigenvalue analysis of SSR performance of TCSC control schemes [17].

Modal analysis is a technique based on modal decomposition. The mathematical model of the linearized study system can be written as a set of differential algebraic equations given by:

$$
\left\{\begin{array}{l}
\dot{X}=A X+B U \\
Y=C X+D U
\end{array}\right.
$$

where $X$ is the state variable vector, $Y$ is the output vector, $U$ is the input vector, $A$ is the state matrix of size $n \times n, B$ is the input matrix of size $n \times r, C$ matrix has a size of $m \times n$ and $D$ is the matrix which defines the proportion of input which appears directly in the output $(m \times r)$.

(1) can be transformed into a set of decoupled dynamic equations by introducing a new state vector $\widetilde{X}$, where $\widetilde{X}=$ $W X$ and $W$ is the left eigenvector matrix. Its inverse is the right eigenvector matrix and is denoted as $V . W, V$ and the state matrix $A$ have the following relationship:

$$
W A V=\Lambda=\left[\begin{array}{llll}
\lambda_{1} & & & \\
& \lambda_{2} & & \\
& & \ddots & \\
& & & \lambda_{n}
\end{array}\right]
$$

The new set of differential and algebraic equations can be written as:

$$
\left\{\begin{array}{l}
\dot{\tilde{X}}=\Lambda \widetilde{X}+W B U \\
Y=C V \tilde{X}+D U
\end{array}\right.
$$

Since $\Lambda$ is a diagonal matrix, the dynamics of each new state variable $\widetilde{X}_{i}$ is now decoupled, i.e., it is determined by its own initial condition, the input and the $i$-th system mode $\lambda_{i}$ but not related to other state variables $\widetilde{X_{j}}(j \neq i)$.

\section{A. Participation Factor}

Participation factor is used to measure the effect of $X_{i}$ on the $k$-th mode. The definition of participation factors for an eigenvalue is given as:

$$
p_{k i}=\frac{\left|V_{i k}\right|\left|W_{k i}\right|}{\sum_{k=1}^{n}\left|V_{i k}\right|\left|W_{k i}\right|}
$$

$p_{k i}$ denotes the impact of the $i$-th state variable on the $k$ th eigenvalue. Participation factor can be computed from the eigenvector matrices $(V$ and $W)$. 
TABLE I

SYSTEM MODES AT DIFFERENT WIND SPEEDS WITH 75\% COMPENSATION LEVEL

\begin{tabular}{c|c|c|c|c}
\hline & Mode 1: $\lambda_{1,2}(\mathrm{~Hz})$ & Mode $2: \lambda_{3,4}(\mathrm{~Hz})$ & Mode 3: $\lambda_{5,6}(\mathrm{~Hz})$ & Mode $4: \lambda_{7,8}(\mathrm{~Hz})$ \\
\hline $7 \mathrm{~m} / \mathrm{s}$ & $4.9 \pm j 123.2(19.6)$ & $-10.4 \pm j 629(100)$ & $-12.7 \pm j 99.1(15.8)$ & $-1 \pm j 5.8(0.92)$ \\
\hline $8 \mathrm{~m} / \mathrm{s}$ & $-2.1 \pm j 121.8(19.4)$ & $-10 \pm j 629.1(100)$ & $-5.7 \pm j 63.2(10.1)$ & $-1.5 \pm j 5.4(0.86)$ \\
\hline $9 \mathrm{~m} / \mathrm{s}$ & $-4.3 \pm j 121.4(19.3)$ & $-9.6 \pm j 629.2(100)$ & $-2.5 \pm j 30.5(4.85)$ & $-1.4 \pm j 2.8(0.45)$ \\
\hline $10 \mathrm{~m} / \mathrm{s}$ & $-5.4 \pm j 120.7(19.2)$ & $-9.3 \pm j 629.4(100)$ & $-5.9 \pm j 27.8(4.42)$ & $0.5 \pm j 4.4(0.70)$ \\
\hline
\end{tabular}

TABLE II

SYSTEM MODES AT 7M/S WIND SPEED WITH DIFFERENT COMPENSATION LEVELS

\begin{tabular}{l|c|c|c|c}
\hline & Mode 1: $\lambda_{1,2}(\mathrm{~Hz})$ & Mode 2: $\lambda_{3,4}(\mathrm{~Hz})$ & Mode 3: $\lambda_{5,6}(\mathrm{~Hz})$ & Mode 4: $\lambda_{7,8}(\mathrm{~Hz})$ \\
\hline $25 \%$ & $-4.4 \pm j 230.6(36.7)$ & $-7.7 \pm j 522.6(83.2)$ & $-3.5 \pm j 97.1(15.5)$ & $-0.9 \pm j 6(0.95)$ \\
\hline $50 \%$ & $-2.6 \pm j 169.6(27.0)$ & $-9 \pm j 582.2(92.7)$ & $-5.2 \pm j 98(15.6)$ & $-0.9 \pm j 5.9(0.94)$ \\
\hline $75 \%$ & $4.9 \pm j 123.2(19.6)$ & $-10.4 \pm j 629(100)$ & $-12.7 \pm j 99.1(15.8)$ & $-1 \pm j 5.8(0.92)$ \\
\hline $95 \%$ & $12 \pm j 105.2(16.7)$ & $-11.4 \pm j 660.5(105)$ & $-19.9 \pm j 86.8(13.8)$ & $-1.1 \pm j 5.7(0.91)$ \\
\hline
\end{tabular}

\section{B. Time Response Coefficients}

Assume that the linear system under discussion has no inputs, then from (3), the decoupled first order equation which describes the dynamics of $\widetilde{X}_{i}$ is given by:

$$
\dot{\widetilde{X}}_{i}=\lambda_{i} \widetilde{X}_{i}
$$

The time-domain response can be given by:

$$
\tilde{X}_{i}(t)=e^{\lambda_{i} t} \widetilde{X}_{i}(0)
$$

where $\widetilde{X}_{i}(0)$ is the initial value of $\widetilde{X}_{i}$ and $\widetilde{X}_{i}(0)=W X_{i}(0)$.

Therefore the time response of the original state vector is given by:

$$
\begin{aligned}
X_{i}(t) & =\sum_{k=1}^{n} V_{i k} \widetilde{X}_{k}(t) \\
& =\sum_{k=1}^{n} V_{i k} e^{\lambda_{k} t} \widetilde{X}_{k}(0) \\
& =\sum_{k=1}^{n} V_{i k} e^{\lambda_{k} t}\left[\sum_{j=1}^{n} W_{k j} X_{j}(0)\right]
\end{aligned}
$$

In another word, the time response of the component in $X_{i}(t)$ which corresponds to eigenvalue $\lambda_{k}$ can be written as:

$$
\begin{array}{ll}
X_{i}^{k}(t) & =C_{i}^{k} e^{\lambda_{k} t} \\
\text { where } C_{i}^{k} & =\sum_{j=1}^{n} V_{i k} W_{k j} X_{j}(0)
\end{array}
$$

Thus, the time response coefficients $C_{i}^{k}$ can be determined by the eigenvector matrices ( $V$ and $W$ ) and the initial conditions of the state variables.

\section{System Modes IDENTIFICATION}

In this paper, maximum power point tracking is modeled. For each wind speed, the wind turbine's rotating speed will have a corresponding optimum value. The following table gives the relationship of the wind speed, the rotating speed and the torque.

Eigenvalue analysis of the study system at $75 \%$ compensation level at different wind speeds are conducted with four oscillatory system modes shown in Table I. These four system modes at different compensation levels are shown in Table II.
TABLE III

WIND SPEED, ROTOR SHAFT SPEED AND MECHANICAL POWER LOOKUP TABLE.

\begin{tabular}{|c|c|c|c|c|c|c|}
\hline$v_{\text {wind }}$ & $7 \mathrm{~m} / \mathrm{s}$ & $8 \mathrm{~m} / \mathrm{s}$ & $9 \mathrm{~m} / \mathrm{s}$ & $10 \mathrm{~m} / \mathrm{s}$ & $11 \mathrm{~m} / \mathrm{s}$ & $12 \mathrm{~m} / \mathrm{s}$ \\
\hline$\omega_{m}$ & 0.75 & 0.85 & 0.95 & 1.05 & 1.15 & 1.25 \\
\hline$P_{m}$ & 0.32 & 0.49 & 0.69 & 0.95 & 1.25 & 1.60 \\
\hline$T_{m}=\frac{P_{m}}{\omega_{m}}$ & 0.43 & 0.58 & 0.73 & 0.90 & 1.09 & 1.28 \\
\hline
\end{tabular}

The first task is to identify the nature of the four modes. From the frequency range, $\lambda_{1,2}$ could be the SSR mode while $\lambda_{3,4}$ represent the super-synchronous mode. $\lambda_{7,8}$ could be the shaft mode and $\lambda_{5,6}$ are difficult to identify.

\section{A. Identification of SSR mode and supersynchronous mode}

The frequency of the electric network resonance mode $f_{n}$ is given by [15]:

$$
f_{n}=f_{e} \sqrt{\frac{X_{c}}{X_{L}}}
$$

where $X_{L}$ is the total inductive reactance, $X_{c}$ is the total capacitive reactance and $f_{e}$ is the nominal system frequency. This network oscillatory mode with a frequency of $f_{n}$ in stators will have a corresponding component induced in rotor circuits with a frequency of $\left( \pm f_{n}-f_{m}\right)\left(f_{m}\right.$ is the frequency corresponding to the rotating speed). Interactions of the stator currents and the rotor currents lead to the electromagnetic torque. Hence in the electromagnetic torque, besides the dc component, there will be two components, one with a frequency of $\left(60-f_{n}\right)$ (complementary of the SSR network mode) and the other with a frequency of $\left(60+f_{n}\right)$ for the supersynchronous mode. In this study, the models are built in a synchronous reference frame. Hence the network mode reflected in a stationary circuit with a frequency of $f_{n}$ has a frequency of $\left(60-f_{n}\right)$ when the stationary circuits are observed from the synchronous rotating reference frame. The supersynchronous mode is reflected in the electromagnetic torque which is not a circuit variable. Hence in the synchronous rotating reference frame, this mode will be observed to have a frequency of $\left(60+f_{n}\right)$.

At $75 \%$ compensation level, an estimation of the electric network resonance mode based on (9) can be performed where $X_{c}$ is the reactance of the series compensation and $X_{L}$ is the total inductive reactance of the system. In this 
TABLE IV

PARTICIPATION FACTOR AT DIFFERENT COMPENSATION LEVEL WITH 7M/S WIND SPEED

\begin{tabular}{c|c|c|c|c|c|c}
\hline & \multicolumn{2}{|c|}{$25 \%$ compensation level } & \multicolumn{2}{c|}{$50 \%$ compensation level } & \multicolumn{2}{c}{ 95\% compensation level } \\
\hline State Variable & $\begin{array}{c}\text { SSR mode } \\
-4.4+j 230.6\end{array}$ & $\begin{array}{c}\text { shaft mode } \\
-0.9+j 6\end{array}$ & $\begin{array}{c}\text { SSR mode } \\
-2.6+j 169.6\end{array}$ & $\begin{array}{c}\text { shaft mode } \\
-0.9+j 5.9\end{array}$ & $\begin{array}{c}\text { SSR mode } \\
12+j 105.2\end{array}$ & $\begin{array}{c}\text { shaft mode } \\
-1.1 \pm j 5.7\end{array}$ \\
\hline q-axis stator current $i_{q s}$ & 0.2304 & 0.0021 & 0.2391 & 0.0032 & 0.3376 & 0.0082 \\
\hline $\mathrm{d}-$ axis stator current $i_{d s}$ & 0.2322 & 0.0607 & 0.2387 & 0.0809 & 0.0448 & 0.1501 \\
\hline $\mathrm{q}-$ axis rotor current $i_{q r}$ & 0.2254 & 0.0025 & 0.2368 & 0.0036 & 0.3471 & 0.0087 \\
\hline $\mathrm{d}-$ axis rotor current $i_{d r}$ & 0.2269 & 0.0728 & 0.2360 & 0.0945 & 0.0444 & 0.1667 \\
\hline $\mathrm{q}$-axis line current $i_{q e}$ & 0.0186 & 0 & 0.0107 & 0 & 0.0013 & 0.0001 \\
\hline $\mathrm{d}-$ axis line current $i_{d e}$ & 0.0182 & 0.0031 & 0.0104 & 0.0043 & 0.009 & 0.0082 \\
\hline turbine speed $\omega_{t}$ & 0 & 0.0773 & 0 & 0.0742 & 0 & 0.0636 \\
\hline machine speed $\omega_{m}$ & 0.0001 & $\mathbf{0 . 3 4 1 4}$ & 0.0003 & $\mathbf{0 . 3 2 0 2}$ & 0.0026 & $\mathbf{0 . 2 4 6 8}$ \\
\hline Torque in mass $1-2 T_{12}$ & 0 & $\mathbf{0 . 4 3 5 3}$ & 0 & $\mathbf{0 . 4 1 4 3}$ & 0 & $\mathbf{0 . 3 4 0 5}$ \\
\hline $\mathrm{q}-$ axis capacitor voltage $v_{q c}$ & 0.0237 & 0.0006 & 0.0135 & 0.0017 & 0.0066 & 0.0061 \\
\hline $\mathrm{d}-$ axis capacitor voltage $v_{d c}$ & 0.0239 & 0 & 0.0137 & 0 & 0.0013 & 0.0002 \\
\hline
\end{tabular}

study $X_{c}$ is $75 \%$ of the line reactance $X_{\text {line }}$ while the total inductive reactance $X_{L}$ should include the line reactance, the transformer reactance and the machine circuit reactance. An estimation finds that $f_{n}$ is about $42 \mathrm{~Hz}$ for $75 \%$ compensation level. Since the synchronous reference frame is used to model the system, this mode reflecting in stationary circuits now becomes $18 \mathrm{~Hz}$ in the model. $\lambda_{1,2}$ has a frequency close to $18 \mathrm{~Hz}$. Therefore, $\lambda_{1,2}$ can be confirmed as the SSR mode. The supersynchronous mode will have a frequency of about $99 \mathrm{~Hz}$, which is close to the frequency range of $\lambda_{3,4}$. Hence, it can be confirmed that $\lambda_{3,4}$ represent the supersynchronous mode.

Another confirmation of Mode 1 as the SSR mode comes from Table II. It can be found that the frequency in the SSR mode decreases with the compensation level increasing. For the SSR mode, the higher the compensation level, the higher its frequency. Observed from the synchronous reference frame, then the frequency of the SSR mode is reducing. Meanwhile, the damping ratio of the SSR mode should decrease with an increasing compensation level due to induction generator effect.

The damping of the SSR mode increases when the wind speed increase. This phenomenon can be explained by induction generator effect. A general expression of the stator current can be given as:

$$
i_{a}=\underbrace{\sqrt{2} A \sin \left(\omega_{e} t\right)}_{i_{s 1}}+\underbrace{e^{-\alpha t} B \sin \left(\omega_{n} t+\theta\right)}_{i_{s 2}}
$$

where $i_{s 1}$ is the component with a frequency of $\omega_{e}$ which is the frequency of the driving voltages of all the generators and $i_{s 2}$ is component with the SSR frequency $\omega_{n}$.

Consider only $i_{s 2}$, the current component due to LC resonance, the steady-state circuit of the induction generator and the transmission network can be expressed as:

In Fig. 2, the slip $s_{1}$ should have the following relationship with the rotating speed $f_{m}$ and the network resonance frequency $f_{n}$ :

$$
\begin{gathered}
s_{1}=\frac{f_{n}-f_{m}}{f_{n}} . \\
s_{1} \begin{cases}\geq 0 & \text { if } f_{n} \geq f_{m} \\
<0 & \text { if } f_{n}<f_{m}\end{cases}
\end{gathered}
$$

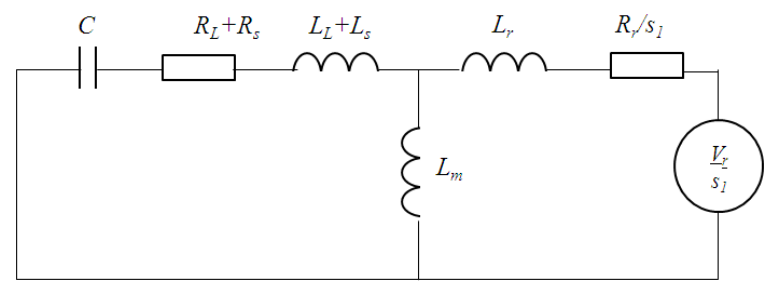

Fig. 2. The equivalent circuit under subsynchronous frequency.

With the wind speed increasing, the corresponding rotating speed $f_{m}$ increases. The frequency of the network resonance at $75 \%$ compensation level $f_{n}$ is less than any rotating speed $f_{m}$. Hence $s_{1}$ is a negative number and its absolute value increases when the wind speed increases. In turn, the absolute value of $R_{r} / s_{1}$ decreases. In turn the circuit has less negative resistance and the damping of the SSR mode increases when the wind speed increases.

\section{B. Identification of shaft mode}

Participation factor analysis in Table. IV shows that the dominant states for $\lambda_{7,8}$ are the rotating masses' speeds and the torque between the two masses of the wind turbine. Hence it can be concluded that $\lambda_{7,8}$ are related to the shaft mode. The shaft mode is closely related to the mechanical torque, the electromagnetic torque and the rotating speed. Hence wind speed has great impact on the mode. When the wind speed is at $10 \mathrm{~m} / \mathrm{s}$, this mode has a negative damping.

\section{Identification of electromechanical mode}

Observing Table III found that the frequency of $\lambda_{5,6}$ changes along with the wind speed. As mentioned, different wind speed corresponds to different rotating shaft speed. At $7 \mathrm{~m} / \mathrm{s}$, the speed is $0.75 \mathrm{pu}$ or $45 \mathrm{~Hz}$. At $8 \mathrm{~m} / \mathrm{s}$, the speed is $0.85 \mathrm{pu}$ or 51 Hz. At $9 \mathrm{~m} / \mathrm{s}$ and $10 \mathrm{~m} / \mathrm{s}$, the rotating speeds are 57 and $63 \mathrm{~Hz}$ respectively. Observation tells that the frequency of the mode is the complimentary of the rotating speed $\left(60-f_{m}\right)$. Thus this mode is conjectured to be related to the mechanical dynamics. Further experiments will be performed to better identify this mode.

The rotor resistance $R_{r}$ is varied. The purpose is to observe if such change has any impact on Mode 3. When the rotor resistance $R_{r}$ changes (from 0.00549 to 0.1 ), the eigenvalue loci 
of the SSR, super synchronous resonance, electromechanical and shaft mode at $7 \mathrm{~m} / \mathrm{s}$ wind speed and $75 \%$ compensation level are shown in the Fig. 3. The shaft mode and the supersynchronous mode are kept relatively constant.Two most notable phenomena are remarked here:

- Increase of $R_{r}$ leads to an increased damping of Mode 3 ;

- Increase of $R_{r}$ leads to a decreased damping of Mode 1 - the SSR mode.

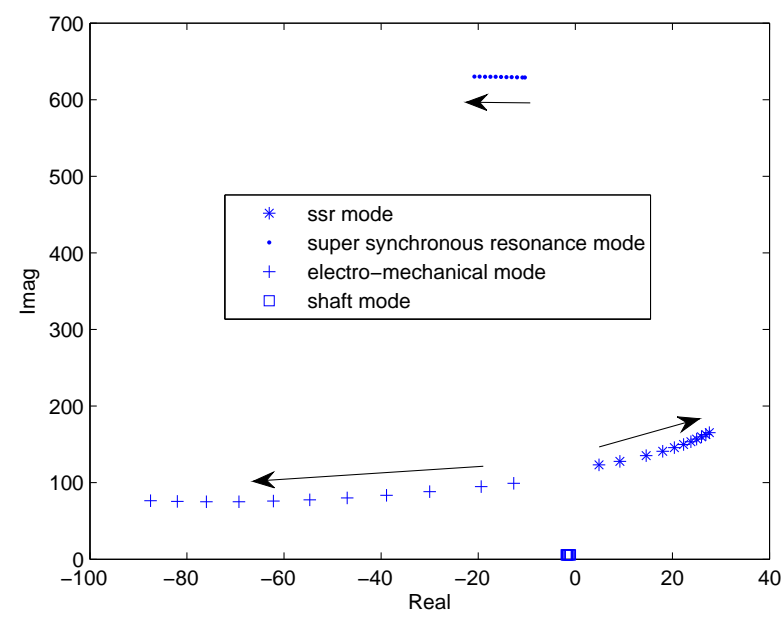

Fig. 3. Eigenvalue loci of the SSR, super synchronous resonance, electromechanical and shaft mode at $7 \mathrm{~m} / \mathrm{s}$ wind speed and $75 \%$ compensation level for increasing rotor resistance $\left(R_{r}=0.00549\right.$ to 0.1$)$.

The decrease of damping in the SSR mode can be explained by the induction generator effect (IGE) using the circuit in Fig. 2. At $75 \%$ compensation level and $7 \mathrm{~m} / \mathrm{s}$ wind speed, $f_{n}$ is less than $f_{m}$ and $s_{1}$ is a negative number. Hence for the SSR mode, when $R_{r}$ increases, the absolute value of $R_{r} / s_{1}$ will be close to and then exceed the sum of the armature and network resistance which lead to negative damping of the circuit or IGE. Therefore, when the rotor resistance $R_{r}$ increases, the damping of the SSR mode will decrease and the SSR mode will move towards the right half plane. The root loci in Fig. 3 corroborate with the above analysis on the SSR mode.

In the rotor circuits, there is a dc component which is decaying and related to the RL circuit. This component if seen from the rotor circuit has a frequency of $0 \mathrm{HZ}$. When this dc component is seen from the synchronous reference frame, the frequency of this component will become $f_{e}-f_{m}$. Detail expressions of the rotor currents for short circuit transients can be found in [18]. Changing $R_{r}$ will increase the speed of decaying of this dc component. If the component is seen in the synchronous reference frame, then its damping is increased. Therefore, Mode 3 is related to the rotor circuit dynamics.

The relationship of Mode 3 and the mechanical dynamics however has not been studied in literature. In the following paragraph, the relationship will be explained. The rotor speed dynamics equation give by:

$$
2 H_{g} \frac{d \omega_{m}}{d t}=T_{m}-T_{e}
$$

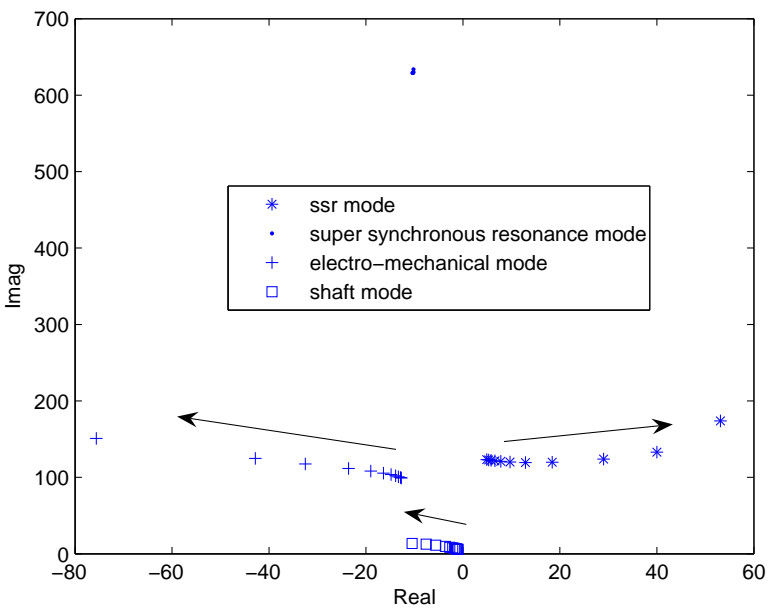

Fig. 4. Eigenvalue loci of the SSR, super synchronous resonance, electromechanical and shaft mode at $7 \mathrm{~m} / \mathrm{s}$ wind speed and $75 \%$ compensation level for a decreasing generator inertia constant $\left(H_{g}=0.9\right.$ to 0.01$)$.

where $\omega_{m}$ is the rotor speed, $T_{m}$ is the mechanical torque and $T_{e}$ is the electromagnetic torque and $T_{e}=i_{q s} i_{d r}-i_{d s} i_{q r}$ where $i_{q s}$ and $i_{d s}$ are the quadrature and direct stator currents and $i_{q r}$ and $i_{d r}$ are the quadrature and direct rotor currents.

From (13), it can be found that the components in rotor currents $i_{q r}$ and $i_{d r}$ corresponding to Mode 3 lead to the component in $T_{e}$ corresponding to Mode 3 and in turn that in $\omega_{m}$. Further, the dynamics of the rotor speed impact Mode 3. This phenomenon can be observed from Table I: when the wind speed changes, the rotating speed changes and Mode 3 has changes in both frequency and damping. Changing the inertia constant $H_{g}$ can also have a significant impact on Mode 3 as shown in Fig. 4.

Therefore, Mode 3 is related to both electrical and mechanical dynamics and is called the electromechanical mode.

\section{Time Domain Responses - PRediction AND CONFIRMATION}

Dynamic responses for state variables are impacted by the dominating system modes and their time response coefficients in those state variables. From Section III, it is known that the time response coefficients in time-domain responses are determined by the eigenvector matrices and the initial conditions. In this study, the different initial conditions are due to the change of the wind speeds and the compensation levels. This section gives the computation results of the time response coefficients from modal analysis, which will be used to analyze and quantify the nonlinear time-domain simulation results.

For different wind speeds (from $7 \mathrm{~m} / \mathrm{s}$ to $10 \mathrm{~m} / \mathrm{s}$ ) and different compensation level, the time response coefficients can be computed according to Section III. Tables V-VIII list the time response coefficients corresponding to each mode for each state variable. Figs. 5-8 show the nonlinear time-domain simulation results of stator current $\left(i_{q s}, i_{d s}\right)$, rotor current $\left(i_{q r}, i_{d r}\right)$, line current $\left(i_{q e}, i_{d e}\right)$, capacitor voltage $\left(v_{c q}, i_{c d}\right)$, electrical torque $\left(T_{e}\right)$ and rotor speed $\left(\omega_{m}\right)$ under different wind speeds (from $7 \mathrm{~m} / \mathrm{s}$ to $10 \mathrm{~m} / \mathrm{s}$ ) with $75 \%$ compensation 

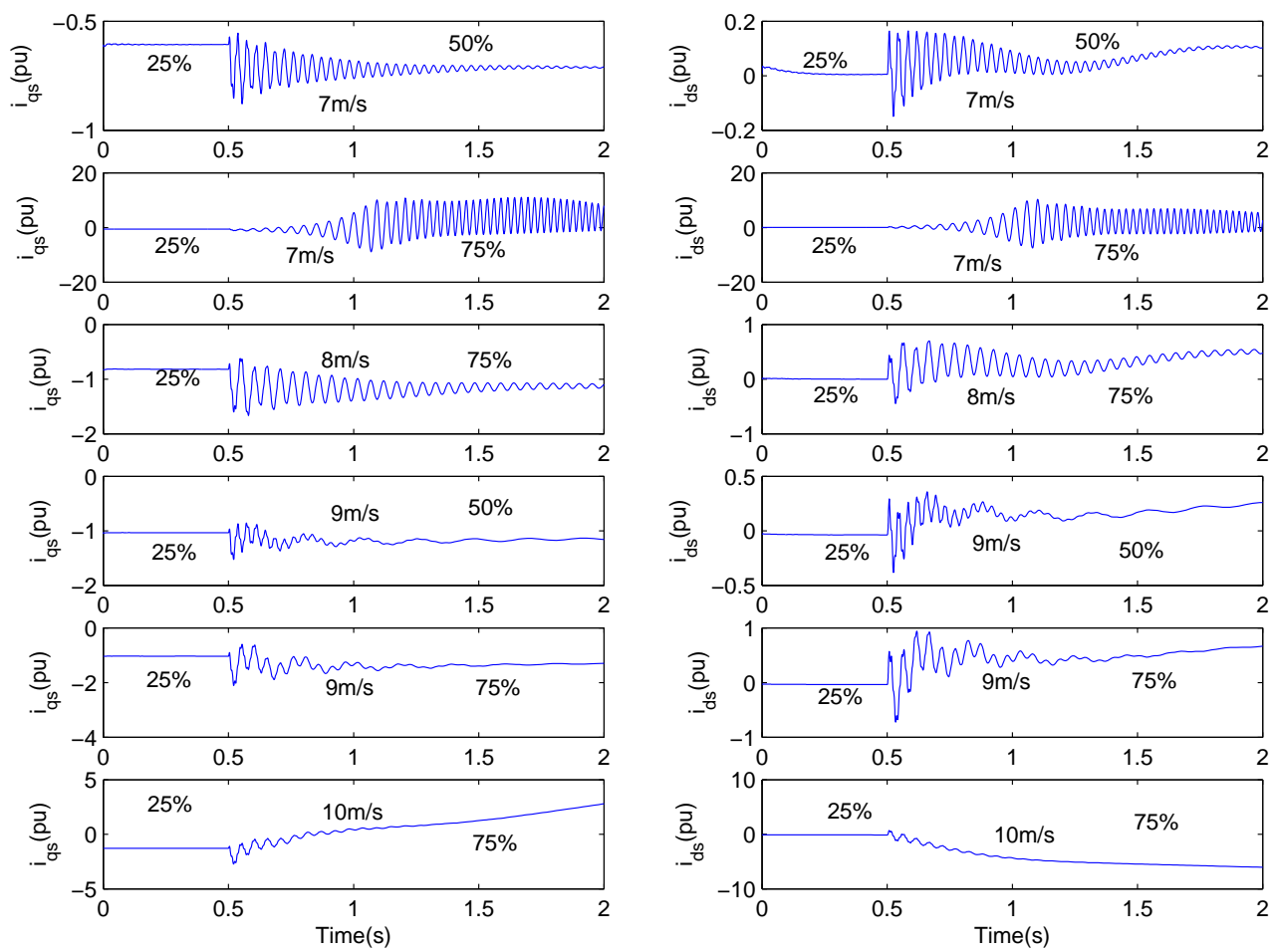

Fig. 5. Simulation results of $i_{q s}$ and $i_{d s}$ under different wind speeds and different compensation levels. At initial condition, the compensation level is $25 \%$.
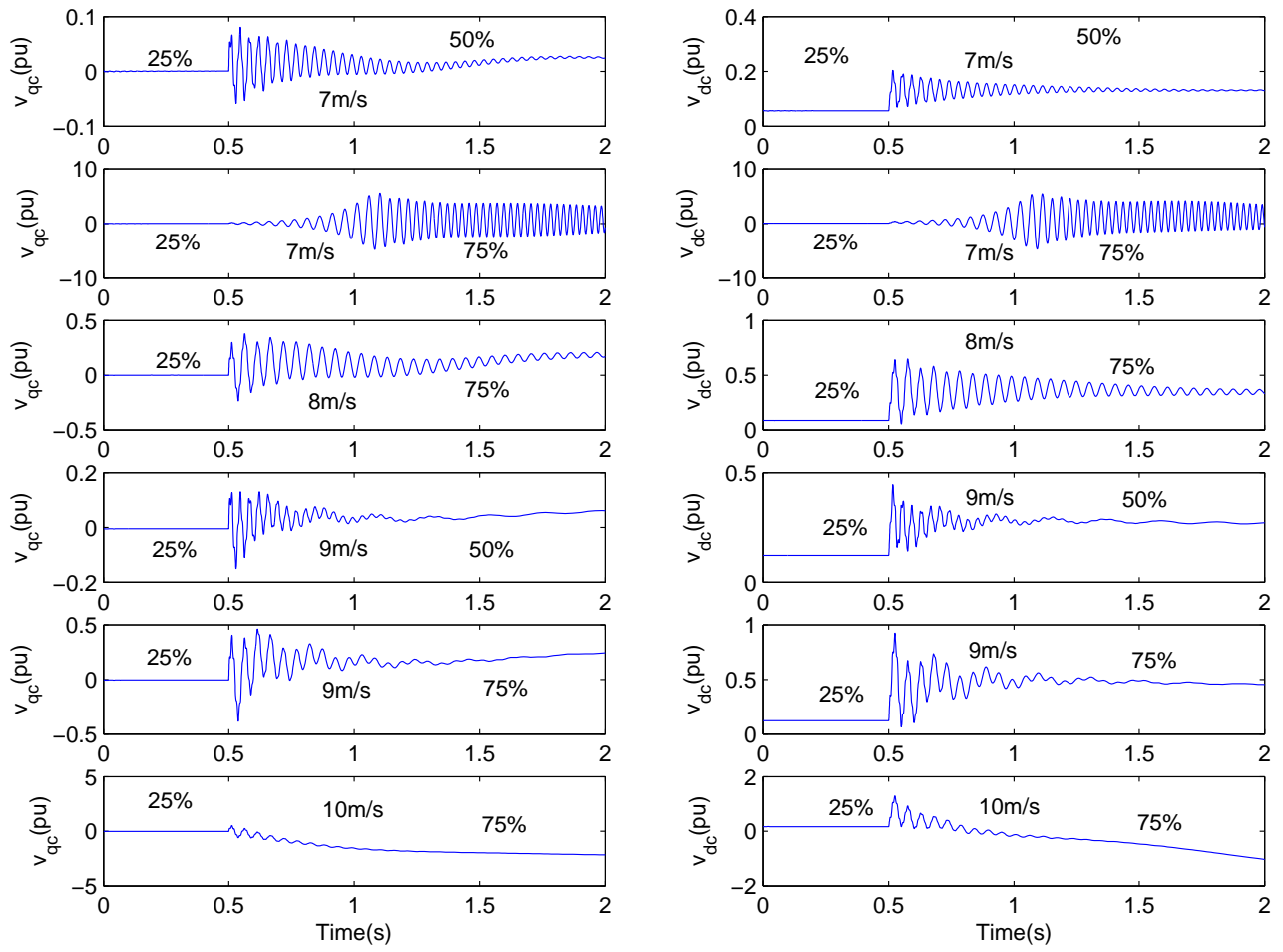

Fig. 6. Simulation results of $v_{c q}$ and $v_{c d}$ under different wind speedsand different compensation levels. At initial condition, the compensation level is $25 \%$. 
TABLE V

TIME RESPONSE COEFFICIENTS AT 7M/S WIND SPEED WITH 75\% COMPENSATION LEVEL

\begin{tabular}{c|c|c|c}
\hline State Variable & $\begin{array}{c}\text { SSR mode } \\
4.9+j 123.2\end{array}$ & $\begin{array}{c}\text { EM mode } \\
-12.7+j 99\end{array}$ & $\begin{array}{c}\text { Shaft mode } \\
-1+j 5.8\end{array}$ \\
\hline $\mathrm{q}-$ axis stator current $i_{q s}$ & 1075 & 1631 & 22 \\
\hline $\mathrm{d}-$ axis stator current $i_{d s}$ & 1061 & 1477 & 111 \\
\hline $\mathrm{q}-$ axis rotor current $i_{q r}$ & 1054 & 1652 & 23 \\
\hline $\mathrm{d}-$ axis rotor current $i_{d r}$ & 1040 & 1495 & 121 \\
\hline $\mathrm{q}-$ axis line current $i_{q e}$ & -1005 & 1394 & 21 \\
\hline $\mathrm{d}-$ axis line current $i_{d e}$ & 992 & 1407 & 110 \\
\hline turbine speed $\omega_{t}$ & 0.005 & 0.011 & 2.02 \\
\hline machine speed $\omega_{m}$ & 3.51 & 6.32 & 8.97 \\
\hline Torque in mass $1-2 T_{12}$ & 1.61 & 3.58 & 104 \\
\hline $\mathrm{q}-$ axis capacitor voltage $v_{q c}$ & 554 & 711 & 41 \\
\hline $\mathrm{d}-$ axis capacitor voltage $v_{d c}$ & 557 & 710 & 8.16 \\
\hline Electrical Torque $T_{e}$ & 777 & 1133 & 23.7 \\
\hline
\end{tabular}

TABLE VI

TIME RESPONSE COEFFICIENTS AT 8M/S WIND SPEED WITH 75\% COMPENSATION LEVEL

\begin{tabular}{c|c|c|c}
\hline State Variable & $\begin{array}{c}\text { SSR mode } \\
-2.1+j 121.8\end{array}$ & $\begin{array}{c}\text { EM mode } \\
-5.7+j 63.2\end{array}$ & $\begin{array}{c}\text { Shaft mode } \\
-1.5+j 5.4\end{array}$ \\
\hline q-axis stator current $i_{q s}$ & 316 & 990 & 57 \\
\hline $\mathrm{d}-$ axis stator current $i_{d s}$ & 315 & 844 & 232 \\
\hline $\mathrm{q}-$ axis rotor current $i_{q r}$ & 309 & 1034 & 61 \\
\hline $\mathrm{d}-$ axis rotor current $i_{d r}$ & 308 & 884 & 253 \\
\hline $\mathrm{q}-$ axis line current $i_{q e}$ & 314 & 818 & 57.2 \\
\hline $\mathrm{d}-$ axis line current $i_{d e}$ & 307 & 816 & 229 \\
\hline turbine speed $\omega_{t}$ & 0.0015 & 0.019 & 2.77 \\
\hline machine speed $\omega_{m}$ & 1.04 & 6.25 & 11.2 \\
\hline Torque in mass $1-2 T_{12}$ & 0.48 & 5.57 & 137 \\
\hline $\mathrm{q}-$ axis capacitor voltage $v_{q c}$ & 171 & 367 & 86 \\
\hline $\mathrm{d}-$ axis capacitor voltage $v_{d c}$ & 173 & 368 & 21.7 \\
\hline Electrical Torque $T_{e}$ & 225 & 706 & 57.6 \\
\hline
\end{tabular}

TABLE VII

TIME RESPONSE COEFFICIENTS AT 9M/S WIND SPEED WITH $75 \%$ COMPENSATION LEVEL

\begin{tabular}{c|c|c|c}
\hline State Variable & $\begin{array}{c}\text { SSR mode } \\
-4.3+j 121.4\end{array}$ & $\begin{array}{c}\text { EM mode } \\
-2.5+j 30.5\end{array}$ & $\begin{array}{c}\text { Shaft mode } \\
-1.4+j 2.8\end{array}$ \\
\hline q-axis stator current $i_{q s}$ & 69 & 494 & 260 \\
\hline $\mathrm{d}-$ axis stator current $i_{d s}$ & 61 & 354 & 627 \\
\hline $\mathrm{q}$-axis rotor current $i_{q r}$ & 60 & 531 & 279 \\
\hline $\mathrm{d}-$ axis rotor current $i_{d r}$ & 60 & 376 & 684 \\
\hline $\mathrm{q}-$ axis line current $i_{q e}$ & 64 & 458 & 254 \\
\hline $\mathrm{d}-$ axis line current $i_{d e}$ & 62 & 320 & 607.5 \\
\hline turbine speed $\omega_{t}$ & 0.003 & 0.05 & 9.87 \\
\hline machine speed $\omega_{m}$ & 0.201 & 6.72 & 10.5 \\
\hline Torque in mass $1-2 T_{12}$ & 0.09 & 12.51 & 265.7 \\
\hline $\mathrm{q}-$ axis capacitor voltage $v_{q c}$ & 34 & 135 & 228 \\
\hline $\mathrm{d}-$ axis capacitor voltage $v_{d c}$ & 35 & 182 & 95.5 \\
\hline Electrical Torque $T_{e}$ & 43 & 355 & 231.6 \\
\hline
\end{tabular}

TABLE VIII

TIME RESPONSE COEFFICIENTS AT 10M/S WIND SPEED WITH $75 \%$ COMPENSATION LEVEL

\begin{tabular}{c|c|c|c}
\hline State Variable & $\begin{array}{c}\text { ssr mode } \\
-5.4+j 120.7\end{array}$ & $\begin{array}{c}\text { EM mode } \\
-5.9+j 27.8\end{array}$ & $\begin{array}{c}\text { shaft mode } \\
0.5+j 4.4\end{array}$ \\
\hline q-axis stator current $i_{q s}$ & 53 & 325 & 51 \\
\hline $\mathrm{d}-$ axis stator current $i_{d s}$ & 55 & 199 & 250 \\
\hline $\mathrm{q}-$ axis rotor current $i_{q r}$ & 52 & 359 & 57 \\
\hline $\mathrm{d}-$ axis rotor current $i_{d r}$ & 53 & 219 & 272 \\
\hline $\mathrm{q}-$ axis line current $i_{q e}$ & 59 & 363 & 55 \\
\hline $\mathrm{d}-$ axis line current $i_{d e}$ & 56 & 210 & 249 \\
\hline turbine speed $\omega_{t}$ & 0.0002 & 0.045 & 1.95 \\
\hline machine speed $\omega_{m}$ & 0.18 & 4.88 & 381 \\
\hline Torque in mass $1-2 T_{12}$ & 0.08 & 9.8 & 72 \\
\hline q-axis capacitor voltage $v_{q c}$ & 31 & 70 & 93 \\
\hline $\mathrm{d}-$ axis capacitor voltage $v_{d c}$ & 32 & 130 & 19 \\
\hline Electrical Torque $T_{e}$ & 38 & 236 & 37 \\
\hline
\end{tabular}

level. The dynamics are initiated at $t=0.5 \mathrm{~s}$ when the original compensation level (25\%) is changed to $50 \%$ or $75 \%$.

Remarks from the observation of Tables V-VIII are listed as:

1) Dominating systems modes are changing with changing operating conditions. For example, at $7 \mathrm{~m} / \mathrm{s}$ and $8 \mathrm{~m} / \mathrm{s}$ wind speed, the dominating mode is the SSR mode alone. The electromechanical mode and the shaft mode have enough damping. When the wind speed is $9 \mathrm{~m} / \mathrm{s}$, the dominating modes are the electromechanical mode and the SSR mode. When the wind speed is $10 \mathrm{~m} / \mathrm{s}$, the dominating modes are the shaft mode and the SSR mode.

2) When the speed is low $(7 \mathrm{~m} / \mathrm{s}$ and $8 \mathrm{~m} / \mathrm{s})$ the $\mathrm{SSR}$ mode is most obvious in the voltages and currents as the corresponding time response coefficients are relatively large. It is not obvious in the torques and speeds.

3) When the wind speed is high, the shaft mode is most obvious in the torques and speeds as the corresponding time response coefficients are large. It is not obvious in electrical variables such as voltages and currents.

4) When the speed is high $(9 \mathrm{~m} / \mathrm{s}$ and $10 \mathrm{~m} / \mathrm{s})$ the electromechanical mode and the shaft mode are dominant in the time-domain responses of the voltages and currents. The SSR mode is no longer dominant. The SSR mode also has a better damping when the wind speed is high.

5) The electromechanical mode can be observed in the electromagnetic torque, the generator speed, and the voltages and currents.

For example, the simulation results of $i_{q s}$ at $8 \mathrm{~m} / \mathrm{s}$ with $75 \%$ compensation level and at $9 \mathrm{~m} / \mathrm{s}$ at $50 \%$ or $75 \%$ show that when the wind speed is low $(8 \mathrm{~m} / \mathrm{s})$, it is the SSR mode dominating the dynamic response; but when the wind speed is high $(9 \mathrm{~m} / \mathrm{s})$, it is the electromechanical mode dominating the dynamic responses since the SSR mode can be damped out fast. At the same operating condition, the shaft mode is more obvious in $d$-axis currents than in $q$-axis from Fig. 5 . For the series capacitor voltages, the shaft mode is more obvious in the $q$-axis variable (Fig. 6). From the time response coefficients tables, the coefficients of the shaft mode in $d$-axis currents are much greater than that in $q$-axis currents. This explains the difference in nonlinear simulation results.

Fig. 7 shows the dynamic responses of the electromagnetic torque $T_{e}$ at different wind speeds and different compensation levels. The dynamic responses confirm remark (1).

The dynamic responses of the rotor speed are shown in Fig. 8. From the time response coefficient table, the response of rotating speed $\omega_{m}$ is determined largely by the electromechanical mode and the shaft mode at all wind speeds and compensation levels. Therefore, the electric network resonance mode or the SSR mode is not obvious in the rotor speed responses.

Study of time response coefficients has potential applications. One example is that it can help choose suitable feedback signals when SSR mitigation is of concern. In conventional synchronous generator systems, torsional interaction is a big concern in SSR phenomena. Unlike such systems, in wind energy systems, due to the low shaft stiffness, the shaft mode has a very low frequency and torsional interaction rarely 


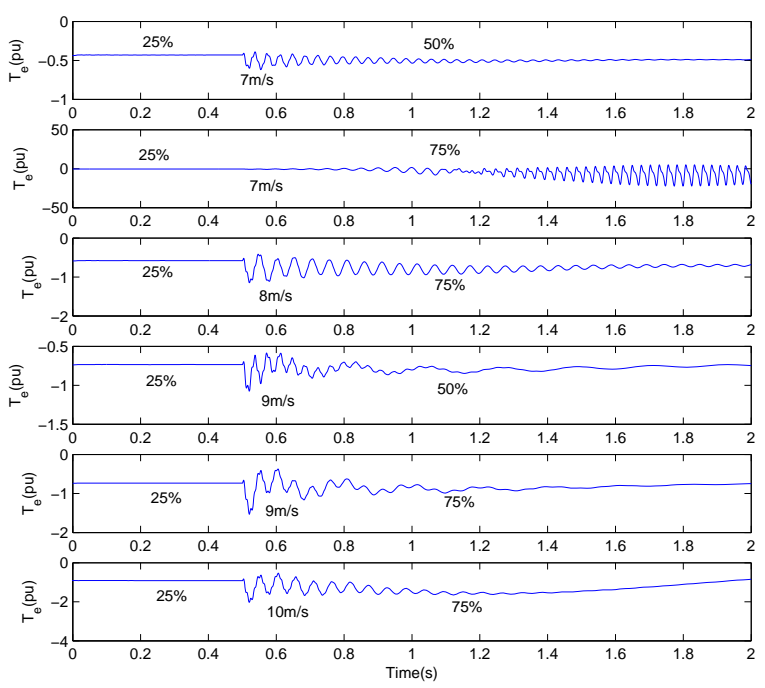

Fig. 7. Simulation results of Te under different wind speeds and different compensation levels. At initial condition, the compensation level is $25 \%$.

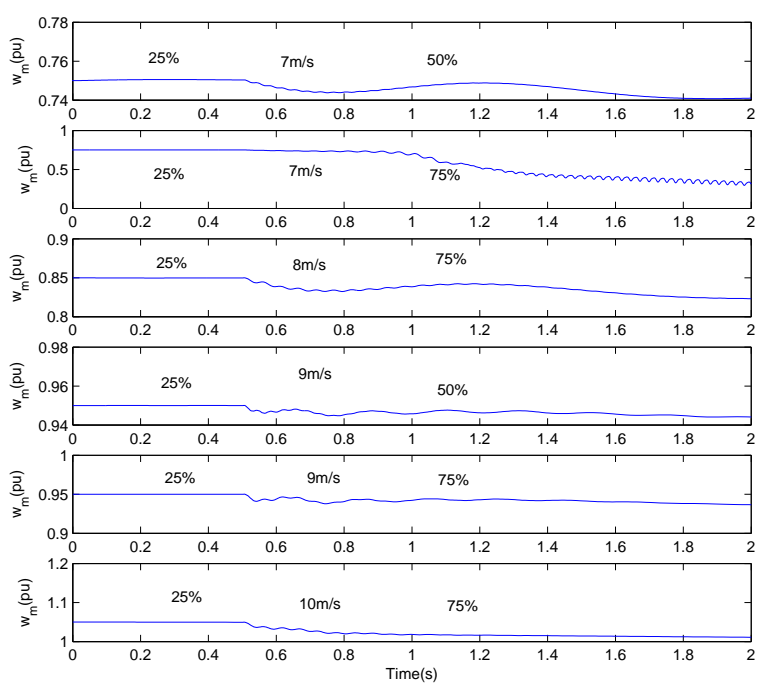

Fig. 8. Simulation results of $\omega_{m}$ under different compensation levels and different compensation levels. At initial condition, the compensation level is $25 \%$.

happens. Rotor speed or frequency has been used as the feedback signal for SSR mitigation in conventional power systems via FACTS devices [19] and in wind energy systems [2], [4]. Our study shows that for wind energy systems, rotor speed does not reflect the network resonance mode well. Hence in such systems, a better choice should be made. Such inquiry was made in a recent submitted paper [20].

\section{CONCLUSION}

Modal analysis is performed for a DFIG-based wind energy system interconnected with a series-compensated electric network. Four system modes are identified, namely, the SSR mode, the super-synchronous resonance mode, the electromechanical mode and the shaft mode using eigenvalue analysis and participation factor. Parameters and operating conditions are varied to confirm the characteristics of those system modes and demonstrate their impact on those system modes. Unique findings documented in this paper include (i) the nature of the electromechanical mode and its relation with the wind speed; (ii) the relationship between the shaft mode and the wind speed, and (iii) time response coefficients computed based on modal analysis in order to predict the dynamic performance of different variables. The predictions are confirmed by nonlinear time-domain simulation results.

\section{APPENDIX}

TABLE IX

PARAMETERS OF A SINGLE 2 MW DFIG AND THE AGgREGATEd DFIG IN NETWORK SYSTEM

\begin{tabular}{|c|c|c|}
\hline Rated power & $2 \mathrm{MW}$ & $100 \mathrm{MW}$ \\
\hline Rated voltage & $690 \mathrm{~V}$ & $690 \mathrm{~V}$ \\
\hline$X_{l s}$ & $0.09231 \mathrm{pu}$ & $0.09231 \mathrm{pu}$ \\
\hline$X_{M}$ & $3.95279 \mathrm{pu}$ & $3.95279 \mathrm{pu}$ \\
\hline$X_{l r}$ & $0.09955 \mathrm{pu}$ & $0.09955 \mathrm{pu}$ \\
\hline$R_{s}$ & $0.00488 \mathrm{pu}$ & $0.00488 \mathrm{pu}$ \\
\hline$R_{r}^{\prime}$ & $0.00549 \mathrm{pu}$ & $0.00549 \mathrm{pu}$ \\
\hline$H$ & $3.5 \mathrm{~s}$ & $3.5 \mathrm{~s}$ \\
\hline$X_{t g}$ & $0.3 \mathrm{pu}(0.189 \mathrm{mH})$ & $0.3 \mathrm{pu}\left(\frac{0.189}{5} \mathrm{mH}\right)$ \\
\hline DC link capacitor C & $14000 \mu F$ & $50 \times 14000 \mu F$ \\
\hline DC link rated voltage & $1200 \mathrm{~V}$ & $1200 \mathrm{~V}$ \\
\hline \hline
\end{tabular}

TABLE $X$

PARAMETERS OF THE NETWORK SYSTEM

\begin{tabular}{|c|c|}
\hline Transformer ratio & $690 \mathrm{~V} / 161 \mathrm{kV}$ \\
\hline Base MVA & $100 \mathrm{MVA}$ \\
\hline$R_{L}$ & $0.02 \mathrm{pu}(5.1842 \Omega)$ \\
\hline$X_{L}$ & $0.5 \mathrm{pu}(129.605 \Omega)$ \\
\hline$X_{C}$ at 50\% compensation level & $64.8 \Omega$ \\
\hline Series compensation C & $40 \mu \mathrm{F}$ \\
\hline Line length & $154 \mathrm{mile}$ \\
\hline
\end{tabular}

TABLE XI

PARAMETERS OF THE SHAFT SYSTEM

\begin{tabular}{|c|c|}
\hline$H_{1}$ & $0.9 \mathrm{~s}$ \\
\hline$H_{2}$ & $4.29 \mathrm{~s}$ \\
\hline$D_{1}$ & $0 \mathrm{pu}$ \\
\hline$D_{2}$ & $0 \mathrm{pu}$ \\
\hline$D_{12}$ & $1.5 \mathrm{pu}$ \\
\hline$K_{12}$ & $0.15 \mathrm{pu}$ \\
\hline
\end{tabular}

\section{ACKNOWLEDGEMENT}

The authors would like to acknowledge NSF for its support through EECS-0901213. This paper is partly supported by China Scholarship Council.

\section{REFERENCES}

[1] IEEE Committee Report, "Terms, definitions, and symbols for subsynchronous resonance oscillations," IEEE Trans. Power App. Syst., vol. 104, pp. 1326-1334, Jun. 1985. 
[2] R. Varma, S. Auddy, and Y. Semsedini, "Mitigation of subsynchronous resonance in a series compensated wind farm using FACTS controllers," IEEE Trans. Power Del., vol. 23, no. 3, pp. 1645-1654, Jul. 2008.

[3] A. Ostadi, A. Yazdani, and R. Varma, "Modeling and stability analysis of a DFIG-based wind-power generator interfaced with a seriescompensated line," IEEE Trans. Power Del., vol. 24, no. 3, pp. 1504 1514, Jul. 2009.

[4] M. S. El-Moursi, B. Bak-Jensen, and M. H. Abdel-Rahman, "Novel STATCOM controller for mitigating SSR and damping power system oscillations in a series compensated wind park," IEEE Trans. Power Electron., vol. 25, no. 2, pp. 429-441, Feb. 2010.

[5] F. Mei and B. Pal, "Modal analysis of grid-connected doubly fed induction generators," IEEE Trans. Energy Convers., vol. 22, no. 3, pp. 728-736, Sep. 2007.

[6] F. Mei and B. C. Pal, "Modelling of dobuly-fed induction generator for power system stability study," Proceedings of IEEE Power \& Energy General Meeting 2008, Jul. 2008.

[7] IEEE Committee Report, "First benchmark model for computer simulation of subsynchronous resonance," IEEE Trans. Power and Apparatus Systems, vol. 96, no. 5, pp. 1565-1672, Sep./Oct. 1977.

[8] N. W. Miller, W. W. Price, and J. J. Sanchez-Gasca, "Dynamic modeling of ge 1.5 and 3.6 wind turbine-generators," GE-Power Systems Energy Consulting, General Electric International, Inc., Schenectady, NY, Oct. 2003.

[9] Z. Miao and L. Fan, "The art of modeling high-order induction generator in wind generation applications," Simulation Modelling Practice and Theory, vol. 16, no. 9, pp. 1239-1253, Oct. 2008.

[10] J. Sun, "Small-signal methods for ac distributed power systemsa review," IEEE Trans. Power Electron., vol. 24, no. 11, pp. 2545-2554, Nov. 2009

[11] C. Zhu, L. Fan, and M. Hu, "Modeling and simulation of a DFIG-based wind turbine for SSR," in North American Power Symposium (NAPS), Mississippi State University, Starkville MS, Oct. 2009.

[12] L. Fan, R. Kavasseri, Z. Miao, and C. Zhu, "Modeling of DFIGbased wind farms for SSR analysis," under review, IEEE Trans. Power Delivery.

[13] C. Zhu, L. Fan, and M. Hu, "Modeling and simulation of a DFIG-based wind turbine for SSR," accepted, IEEE PES General Meeting 2010.

[14] G. Rogers, Power System Oscillations. Kluwer Academic Publishers, 2000.

[15] P. Anderson, B. Agrawal, and J. V. Ness, Subsynchronous Resonance in Power Systems. IEEE Press, 1990.

[16] P. Kundur, Power System Sability and Control. McGraw Hill, 1994.

[17] S. Joshi and A. Kulkarni, "Analysis of ssr performance of TCSC control schemes using a modular high bandwidth discrete-time dynamic model," IEEE Trans. Power Syst., vol. 24, no. 2, pp. 840-848, May 2009

[18] D. D. Li, "Analysis and calculation of short circuit current of doubly fed induction generator," in IEEE PES Transmission and Distribution Conference and Exposition, Chicago, IL, Apr. 2008.

[19] N. Hingorani and L. Gyugyi, Understanding FACTSConcepts and Technology of Flexible AC Transmission System. New York: IEEE Press, 2000.

[20] L. Fan and Z. Miao, "Mitigating SSR using DFIG-based wind generation," submitted to IEEE Trans. Power Delivery. 